\title{
Variation in demand for Accident and Emergency departments in England from 1974 to 1985
}

\author{
P C MILNER, J P NICHOLL, AND B T WILLIAMS \\ From the Medical Care Research Unit, Department of Community Medicine, University of Sheffield Medical \\ School, Beech Hill Road, Sheffield S10 2RX
}

SUMMARY Over the period 1974-85 the range of mean annual new attendance rates at Accident and Emergency departments among English health districts was 36-673 per 1000 residents. The socio-economic diversity of these districts explained only one-third of the variation. The rates rose significantly $(p<0.05)$ in 89 per cent of districts over the twelve years. Again, socio-economic variation only partly explained differences in district trends. Increases were greater among districts with higher mean rates. In order to plan first-contact care rationally we need a better understanding of the factors underlying these trends.

Annual new attendance rates at Accident and Emergency (A \& E) departments vary considerably between health authority regions in England. ${ }^{12}$ The highest annual rate in 1983 was 266 per 1000 resident population for the North East Thames region and the lowest was 137 for East Anglia. ${ }^{2}$ These regional figures probably hide much greater inter-district differences.

As well as these geographical variations there have also been striking changes with time. The number of new attendances at A \& E departments per 1000 population in England has been rising constantly since the late 1950s. ${ }^{12}$ Between 1961 and 1972 the annual rate for England rose from 105 to 171 (a $63 \%$ increase) and between 1973 to 1983 it rose from 180 to 212 (an $18 \%$ increase). Similar secular trends have been noted in the USA. ${ }^{3}$ Such differences in temporal changes make uniform forecasting, and hence accurate planning of investments and resource allocation for A \& E departments, difficult. Moreover, about 10 per cent of $\mathrm{A} \& \mathrm{E}$ cases are admitted as inpatients, ${ }^{45}$ so that A \& E work-load forecasts have repercussions for levels of inpatient planning. Furthermore, both the geographical and the temporal variability in A \& $E$ attendance rates pose the normative question of whether an "appropriate" level of demand for these departments can be estimated.

There have been attempts in a few areas in Great Britain to explain temporal trends, ${ }^{6}$ but without explaining the very great geographical and temporal differences which occur in a way which could be used to predict and, still less, control demand. In this paper we describe these geographical and temporal variations which have occurred over more than a decade and seek an explanation in what is known of the socio-economic characteristics of the populations served.

\section{Methods}

The annual number of new attendances at $\mathrm{A} \& \mathrm{E}$ departments for each English health district between 1974 and 1985 reported in the SH3 statistical returns was obtained from the statistics division of the Department of Health and Social Security. The 191 health district areas existing in 1985 were used as a basis for comparison for the whole period. Thus for any health district with different boundaries prior to 1985 the annual numbers of new attendances of the former health district populations were apportioned to the new health districts. Hence some old health district's returns were amalgamated, whereas those of others were divided among the new health districts. In a few districts where coterminosity between the old and the new areas had not been observed, individual A \& E department returns were disaggregated and reattributed to the new areas. The only new health district for which this approach could not be used was Milton Keynes where a completely new district general hospital became operational in 1984. Therefore Milton Keynes was amalgamated with Northampton health district, whose hospitals had previously met the demand for A \& E services from Milton Keynes residents, and they were considered as one for the whole period, producing 190 districts for 
study. A \& E SH3 returns for Hammersmith Hospital, which is directly administered by the Department of Health and Social Security, were allocated to Riverside health district because of its geographical location. There were several other special health authority A \& E SH3 returns which could not be apportioned. The net effect of this is to understate slightly the demand for A \& E facilities in London. Several statistical recording errors were discovered at source and corrected.

The numbers resident in each England health district for 1974 to 1985 were extracted from the most up-to-date versions of the revised, final, or initial resident population mid-year estimates contained in the Office of Population Censuses and Surveys (OPCS) monitor PP1 series. ${ }^{7}$ These are based on the same 1985 health district areas as were used to calculate the annual number of new attendances at A \& $\mathrm{E}$ departments for each health district over this period. There will inevitably be major mismatches between $\mathrm{A} \& \mathrm{E}$ catchment populations and health district populations in some conurbations.

The socio-economic status of health districts was classified using the results of the cluster analysis of the 1981 census small area statistics performed by OPCS. ${ }^{8}$ The six derived categories in this classification can be labelled, roughly, as high status, rural, town, city, local authority housing, and London. A more complete description is given in the Appendix.

The mean of the annual rates for the 12 years 1974-85 was employed to represent the underlying level of demand for A \& E facilities in each health district. Similarly the direction and magnitude of any trend in the annual rate for each health district in this period was assessed using the simple linear regression coefficient of this rate against time in years.

The data were analysed using the SPSS-X package on an IBM mainframe computer. Differences in both the mean and the trend of the annual rates among the categories were assessed using the Kruskal-Wallis one-way analysis of variance by ranks. In order to assess the relationship between the underlying level of the use of a district's A \& E facilities and its trend over this 12-year period, the Spearman rank correlation coefficient between the mean annual rate and the simple linear regression coefficient of the annual rate against time was calculated. The choice of these two variables avoids the artefactual negative correlation between an initial value and any subsequent change. ${ }^{9}$

\section{Results}

The frequency distribution of the mean annual rate of new attendances per 1000 resident population at A \& E departments for the 190 English health districts studied from 1974 to 1985 is shown in fig 1. This

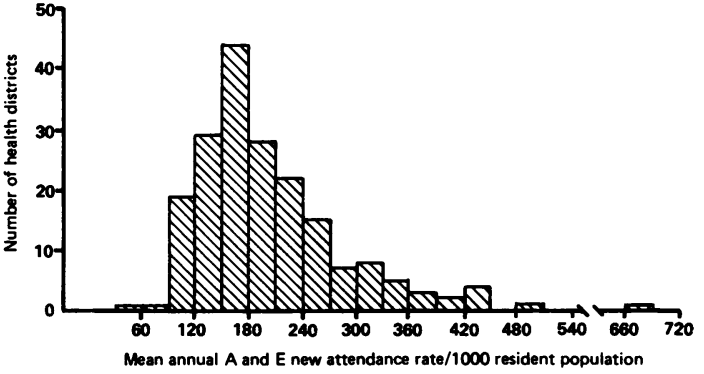

Fig 1 Mean annual new attendance rate at $A \& E$ departments among English health districts for 1974 to 1985.

distribution is positively skewed with a median of 181 and an interquartile range of 89. Its range is eighteenfold, from 36 (Halton) to 673 (Paddington). Socioeconomic classification of the health districts explains $34 \%$ of this variation, with the more advantaged districts having significantly lower rates than the less advantaged (table and fig 2). However, considerable

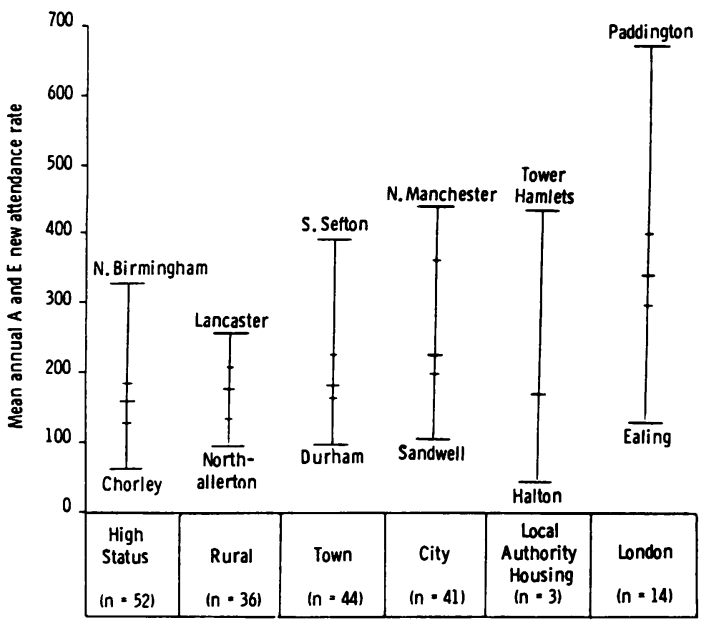

Socio-economic category of health district

Fig 2 The median, interquartile range and range of the mean annual new attendance rates at $A \& E$ departments for each socio-economic category of health district. (The socioeconomic categorisation is explained in the Appendix.)

differences are still found within each socio-economic category, as is evident from fig 2 . Thus for health districts classified as being most like towns the range is from 94 (Durham) to 393 (South Sefton), and for those classified as high status residential areas the range is 64 (Chorley) to 330 (North Birmingham).

The variability in the trends in the annual rate from 1974 to 1985 is illustrated in fig 3, which is the frequency distribution of the simple linear regression coefficients of this rate against time in years. There is a 
Table Analysis of the variance in the mean annual $A \& E$ new attendance rate and of the trend of this annual rate among English health districts from 1974 to 1985 according to socio-economic category using the Kruskal-Wallis ranking method.

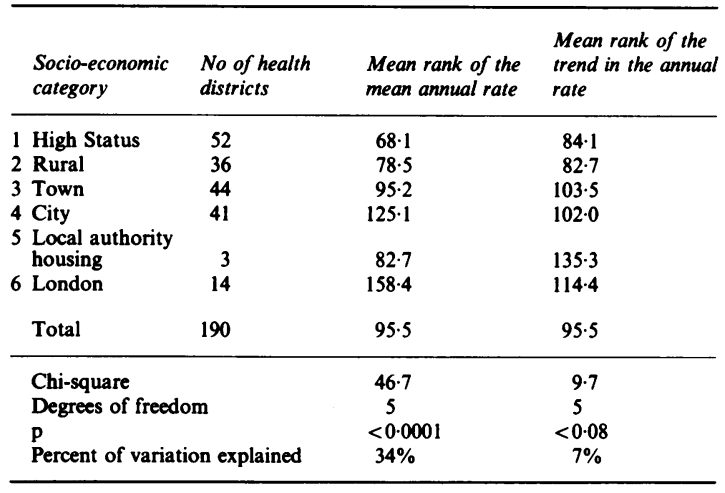

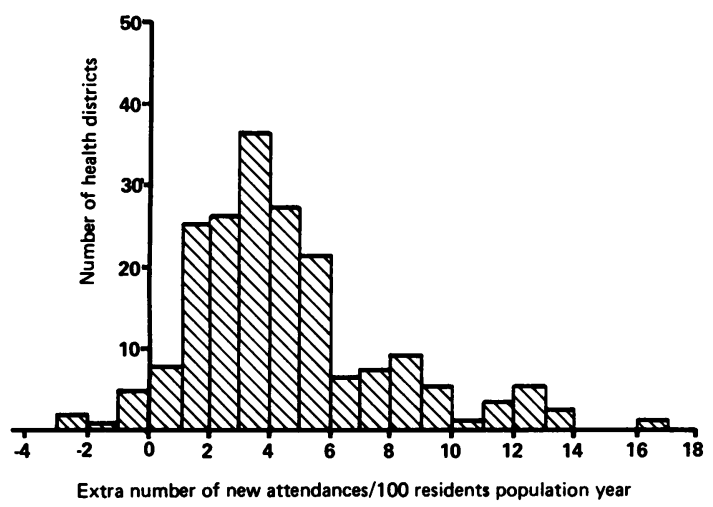

Fig 3 Estimated extra number of new attendances at $A \& E$ departments per 1000 residents per year from 1974 to 1985 in English health districts. (Estimated by the simple linear regression coefficient of annual new attendance rate against time in years.)

statistically significant $(\mathrm{p}<0.05)$ rising trend in 169 $(89 \%)$ of the 190 health districts. The median rate of growth was four additional patients per 1000 population per year, with a range from -3 (Central Birmingham) to +16 (North Birmingham). Socioeconomic classification of the health districts explains only $6 \%$ of this variation in rates of growth. The distributions of the regression coefficient within each of the six socio-economic categories tend to differ significantly from one another (table). As before, great variation in these trends is found within each socioeconomic category. For example, in high status residential districts the range is from Bromsgrove $(-3)$ to Bexley $(+13)$. In particular, the annual rate has grown more quickly in urban areas and industrial areas than rural areas and non-industrial areas (table).
The Spearman rank correlation coefficient between the mean annual rate and the time trend as estimated by its simple linear regression coefficient was +0.38 $(p<0.01)$. Thus the annual rate in districts where the average level of demand was high grew significantly more quickly than in districts where it was low.

\section{Discussion}

Studies of A \& E department attenders in Central London, ${ }^{4}$ Arbroath, ${ }^{10}$ and Romford ${ }^{11}$ have estimated that for $57 \%, 58 \%$, and $54 \%$ of patients respectively diagnosis and treatment could have been managed by a GP. Whether people with minor conditions seek medical care from a GP or from an A \& E department or whether they treat themselves or seek care from medically unqualified sources depends on several factors. First, there is the person's situation when the need arises. This has at least four dimensions: (i) the distance from home ${ }^{12}$ and medical care, ${ }^{13}$ (ii) the social context; ${ }^{12} 14$ (iii) the extent to which social roles are interrupted; 14 and (iv) the amount of social support available. ${ }^{12} 14$ Second, there are a group of personal 0 characteristics, such as age, ${ }^{410} 1213$ sex, 4101215 i marital status, ${ }^{16}$ social class, ${ }^{15} 16$ distance of usual ${ }^{\mathbb{\Phi}}$ 을 residence from A \& E departments, ${ }^{12} 1718$ whether $\stackrel{\odot}{\Phi} \rightarrow$ registered with a local GP, ${ }^{19}$ and distance of place of $\underset{D}{\infty}$ residence from the GP's surgery. ${ }^{17}$ Third, there are individual health beliefs and expectations which set a threshold for attending. ${ }^{14}$ Finally, barriers to attending for medical care may be erected by the service in the attitudes, policies and organisation which it fosters. Self-imposed and service-provided obstacles are not independent of one another.

The public threshold for seeking medical care appears to be falling. ${ }^{20}$ However, attendance at the A \& E department rather than the GP's surgery reflects the beliefs that GPs are increasingly unable to treat minor injuries, ${ }^{11} 2122$ that A \& E department are for treatment and not diagnosis, ${ }^{1423}$ and that GPs are inaccessible at certain times of the day. ${ }^{12} 16$

Some of these beliefs may be well-founded. General practitioners are indeed less willing to perform minor surgical procedures. ${ }^{1121}$ The use of appointment systems in general practice has increased from $15 \%$ of practices in 1964 to $74 \%$ in $1977,{ }^{21}$ and this has been reported as a reason for preferring to attend an $\mathrm{A} \& \mathrm{E}$ department. ${ }^{11} 1418$ Furthermore, the use of receptionists and GP deputising services ${ }^{24}$ may also be barriers to consulting.

Barriers to attending A \& E departments tend to be more explicit. Prominent notices may state that only serious accidents and emergencies will be seen. Medical, nursing or administrative staff may reinforce this-in effect, a form of triage. In addition, long waiting times may deter attendance. On the other hand 
the location in inner cities of an A \& E department is associated with disproportionately greater use of it by local residents. ${ }^{3416}$

Geographical and temporal variability in the size of these "obstacles" will undoubtedly explain some of the variation in $\mathrm{A} \& \mathrm{E}$ new attendance rates. Nevertheless, the wide variation in A \& E department use is still startling. It is doubtful whether there is such widespread variation in the true incidence of accidents and emergencies. Accurate, population-based incidence information is not available in the United Kingdom, unlike the United States where the National Health Survey reports this annually. ${ }^{25} 26$ Undoubtedly, some of the variation is due to the use in these calculations of resident district populations instead of estimated A \& E department catchment populations. However, this cannot conceivably account for more than a small proportion of the 18-fold variation in A \& E attendance rates reported here. For example, even if, in reality, individual use was uniform throughout the country and the catchment populations of some health districts were twice the size, and others half the size of the actual resident population, this would give rise to only a four-fold variation in the $A \& E$ attendance rate. Neither can the use of resident population be responsible for the observed systematic increase in the use of A \& E departments in virtually all the districts.

Our results show that the increase in the use of A \& E departments is not evenly distributed, and a few districts showed static or even declining levels of use. The more urban and industrial areas had the greatest increases in utilisation rates. Moreover, those health districts which already had high A \& E utilisation rates in 1974 showed greater increases than those with initially lower rates, although this only explained $15 \%$ of the variation. However the direction of this association is inappropriate when consideration is given to geographical equity. Districts with relatively low $A$ \& E use could be judged to be inadequately provided for and the finding that their use has grown less than those districts with higher use is of particular concern. The high district rates in 1974 resulted from the net interaction of many forces over preceding years and there is no reason to suppose that this net effect should have diminished subsequently. For example, the depopulation of the inner cities may have left behind a residual population who were more disposed to using $\mathrm{A} \& \mathrm{E}$ departments rather than general practice. London, in particular, has higher rates of use of A \& E facilities and also faster growth patterns, as we have shown.

In the United Kingdom, which has a communitybased, first-contact medical service available 24 hours a day, there is much debate about what kind of health care A \& E departments should provide. ${ }^{1127-29}$ Some types of need are currently met both by general practitioners and A \& E departments, possibly with different economic implications. ${ }^{30}$ It is essential therefore to try to understand what determines changes in A \& E department usage. Only then can the appropriateness of existing patterns of health care delivery be judged, and planning of services proceed rationally.

We thank Mr. John Charlton and his colleagues in the Statistics and Research Division of the Department of Health and Social Security at Hannibal House, The Elephant and Castle, London and the North Flyde Central Offices, Norcross, Blackpool for providing the SH3 returns of Accident and Emergency attendances. The Medical Care Research Unit is supported by the Department of Health and Social Security and Trent Regional Health Authority.

\section{References}

${ }^{1}$ Department of Health and Social Security. Health and personal social services statistics for England, 1975 Edition. London: HMSO, 1975.

2 Department of Health and Social Security. Health and personal social services statistics for England, 1985 Edition. London: HMSO, 1985.

${ }^{3}$ Davidson SM. Understanding the growth of emergency department utilisation. Med Care 1978; 16: 122-4.

${ }^{4}$ Fairley J, Hewett WC. Survey of casualty departments in Greater London. Br Med J 1969; ii: 375-7.

${ }^{5}$ Weinerman ER, Rutzen SR, Pearson DA. Effects of medical 'triage' in hospital emergency service. Pub Health Rep 1965; 80: 389-99.

6 Watson J, Robinson E, Marden K, Crawford RE. Changes in demand for initial medical care in general practice and hospital A and E departments. Br Med J 1979; ii: 365-8.

${ }^{7}$ Office of Population Censuses and Surveys. OPCS Monitor series: PP1 84/2, 84/4, and 86/2. London: Government Statistical Service, 1984 and 1986.

${ }^{8}$ Craig JA. 1981 Socio-economic classification of local and health authorities of Great Britain. OPCS studies on medical and population subjects No. 48. London: HMSO, 1985.

${ }^{9}$ Gill JS, Zezulka AV, Beevers DG, Davies P. Relation between initial blood pressure and its fall with treatment. Lancet 1985; i: 567-9.

${ }^{10}$ Morris JB, Hird MD. A survey of new attenders at the Accident and Emergency department of a small specialist hospital-Angus District. Health Bull 1979; 37: 108-20.

11 Myers D. Management of minor medical problems and trauma: general practice hospital? J Roy Soc Med 1982; 75: 879-83.

12 Calnan M. The functions of the hospital emergency department: a study of patient demand. $J$ Emerg Med 1984; 2: 57-63.

${ }^{13}$ Russell IT. British patients' choice of care for minor injury: a care-study of separate sample logistic discrimination. In American statistical association. Proceedings of the 1977 Social Statistics Section. Washington: American Statistical Association, 1978.

${ }^{14}$ Holohan AM. Accident and Emergency departments: illness and accident behaviour. In Stacey $\mathrm{N}$, ed: The Sociology of the NHS. London: Sociological review monographs, 1976; 22: 111-9. 
${ }^{15}$ Lewis B, Bradbury Y. Why patients choose A \& E. Health Soc Services J 1981; Sept 18: 1139-42.

16 Wienerman ER, Ratner RS, Robbins A, Lavenhar MA. Determinants of use of hospital emergency services. $\mathrm{Am} \mathrm{J}$ Public Health 1966; 56: 1037-56.

${ }^{17}$ Dixon PN, Morris AF. Casual attendances at an Accident Department and a Health Centre. Br Med J 1971; iv: 214-6.

18 Ingram DR, Clarke DR, Murdie RA. Distance and the decision to visit an emergency department. Soc Sci Med 1978; 12: 55-62.

19 Wilkinson A, Dazantizis G, Williams DJ, Dewar RAD, Bristow KM, Miller DL. Attendance at a London Casualty department. J Roy Coll Gen Pract 1977; 27: 727-33.

20 Office of Population Census and Surveys Monitor series 1986; MB5 86/1.

${ }^{21}$ Cartwright A, Anderson R. General practice revisited. London: Tavistock Publications, 1981.

22 Davies T. Accident department or general practice? $\mathrm{Br}$ Med J 1986; 291: 241-3.

${ }^{23}$ Fisher J. Self-referral to an Accident and Emergency Department. Nursing Times 1981; 77: 196-201.

\section{Appendix}

The Office of Population Censuses and Surveys 1981 socio-economic classification of health authorities. ${ }^{7} \mathrm{~A}$ summary of the constituent clusters of the six families with their appropriate labels is shown in the table.
${ }^{24}$ Williams BT, Dixon RA, Nicholl JP. Provision of first contact care out of hours in four urban areas in England. Br Med I' 1985; 291: 1689-92.

${ }^{25}$ National Center for Health Statistics, Moss AJ, Parsons VL. Current estimates from the National Health Interview Survey, United States, 1985. Vital and Health Statistics. Series 10, No. 160. DHSS Pub. No. (PHS) 86-1588. Washington: U.S. Government Printing Office, 1986.

${ }^{26}$ National Center for Health Statistics, Collins JG. Types of injuries and impairments due to injuries, United States. Vital and Health Statistics. Series 10, No. 159. DHSS Pub. No. (PHS) 87-1587. Washington: U.S. Government Printing Office, 1986.

${ }^{27}$ Mestitz PA. A series of 1817 patients seen in a casualty department. Br Med J 1957; ii: 1108-9.

${ }_{29}^{28}$ Fry L. Casualties and casuals. Lancet 1960; i: 163-5.

${ }^{29}$ House of Commons expenditure committee. Fourth Report from the expenditure committee session 1973-74: Accident and Emergency services. London: HMSO, 1974.

${ }^{30}$ Steele R, Lees REM, Latchment B, Spasoff RA. Cost of primary health care services in the emergency department and the family physician's office. J Can Med Ass 1975; 112: 1096-9.

\begin{tabular}{|c|c|c|c|}
\hline & mily label & Subfamily label & Cluster label \\
\hline \multirow{2}{*}{\multicolumn{2}{|c|}{1 High Status }} & $\begin{array}{l}\text { Established } \\
\text { high status }\end{array}$ & $\left\{\begin{array}{l}\text { Commuting } \\
\text { Suburban } \\
\text { Outer London }\end{array}\right.$ \\
\hline & & $\begin{array}{l}\text { Higher status } \\
\text { Growth }\end{array}$ & ( $\begin{array}{l}\text { Smaller, less urbanised, growth } \\
\text { Larger, more urbanised, growth }\end{array}$ \\
\hline & Rural & Rural & $\left\{\begin{array}{l}\text { Rural with transient population } \\
\text { Remoter rural } \\
\text { Less remote, mainly rural }\end{array}\right.$ \\
\hline & & Resort \& retirement & Resort \& retirement \\
\hline \multirow[t]{2}{*}{3} & Town & $\begin{array}{l}\text { Mixed town \& country } \\
\text { with some industry }\end{array}$ & $\left\{\begin{array}{l}\text { More rural with industry } \\
\text { Towns with some surrounding industry } \\
\text { More industrial }\end{array}\right.$ \\
\hline \multirow{2}{*}{\multicolumn{2}{|c|}{4 Cities }} & $\int$ Traditional manufacturing & $\left\{\begin{array}{l}\text { The Black Country \& similar } \\
\text { Pennine towns \& similar } \\
\text { Cities \& more industrial service centres }\end{array}\right.$ \\
\hline & & Service centres \& cities & {$\left[\begin{array}{l}\text { Greenwich } \\
\text { Less industrial service centres }\end{array}\right.$} \\
\hline 5 & Local authority housing area & Areas with much local authority housing & {$\left[\begin{array}{l}\text { Maturer new towns } \\
\text { Tower Hamlets }\end{array}\right.$} \\
\hline \multirow{2}{*}{\multicolumn{2}{|c|}{6 London }} & Parts of Inner London & {$\left[\begin{array}{l}\text { Ealing, Hounslow \& Slough } \\
\text { Brent, Haringay \& Lambeth } \\
\text { Eastern Boroughs }\end{array}\right.$} \\
\hline & & Central London & Central London \\
\hline
\end{tabular}

